\title{
Effects of prolonged administration of anti-cumulus oophorus antibody on reproduction in mice
}

\author{
J. Tesarik, J. Testart and F. Nomé \\ INSERM Unité 187, Service de Gynécologie-Obstétrique, Hôpital Antoine-Béclère, 92141 Clamart, \\ France
}

\begin{abstract}
Summary. Mice were passively immunized over 6 weeks with contraceptive doses of an anti-cumulus oophorus antibody preparation. The persistence of oestrus, accompanied by complete inhibition of conception, was observed throughout treatment. After cessation of treatment, fertility was restored within 2 weeks. Histological examination did not reveal any depletion of the ovarian oocyte stock. These results warrant further research into the nature of cumulus antigens and their use in active immunization studies.
\end{abstract}

Keywords: anti-cumulus antibody; immunocontraception; mouse; sexual behaviour; folliculogenesis

\section{Introduction}

One of the current directions in contraceptive vaccine development implies immunological interference with fertilization using antibodies directed to the zona pellucida, an acellular glycoprotein coat surrounding the ovulated oocyte (for review see Henderson et al., 1988). Passive immunization of mice (Sacco, 1979; Aitken et al., 1981; Tsunoda et al., 1981) and rats (East et al., 1984, 1985) with antibodies to the zona pellucida produced reversible contraception by preventing zona penetration by spermatozoa without obvious side effects. However, active immunization with zona pellucida antigens has been repeatedly reported to result in considerable ovarian histopathology and dysfunction in various mammalian species (Wood et al., 1981; Mahi-Brown et al., 1982, 1985, 1988; Gulyas et al., 1983; Sacco et al., 1983, 1987; Skinner et al., 1984).

Recent observations on multiple roles of the cumulus oophorus, another component of the extracellular coat surrounding the ovulated oocyte, in fertilization (Tesarik et al., 1988, 1990a; Siiteri et al., 1988; Meizel et al., 1990; for review see Tesarik \& Testart, 1989) and the demonstrated inhibition of human fertilization in vitro by antibodies to the human cumulus intercellular matrix (Tesarik, 1989) have prompted us to adopt an alternative strategy for contraceptive vaccine development, implicating cumulus antigens as antibody targets. This approach is based on the reasoning that antibodies to components of the extracellular matrix of the human cumulus oophorus, a secretory product of cumulus cells which appears late in preovulatory development, will probably confine the antibody action to only one preovulatory follicle in each cycle, unlike antibodies to the zona pellucida that develops early in folliculogenesis.

Before examination of the anti-cumulus antibody action in active immunization experiments, we analysed the effects of passive immunization of anti-cumulus antibodies on fertility in mice and found a reversible inhibition of fertility after a single antibody administration (Tesarik et al., 1990b). The present study was undertaken to examine the effects of prolonged passive immunization with anti-cumulus antibodies on the sexual and reproductive functions, including the possible effects on the ovarian oocyte pool. 


\section{Materials and Methods}

Animals. Albino mice aged 4 weeks were purchased from Centre d'Elevage R. Janvier (Le Genest-St-Isle, France) and kept at $20^{\circ} \mathrm{C}$ and in a standard regimen of light and dark for at least 4 days before allocation to experiments.

Anti-cumulus oophorus antibody. Anti-cumulus oophorus antiserum and its immunoglobulin fraction (anticumulus Ig) were prepared as described in detail previously (Tesarik et al., 1990b). Briefly, mouse cumulus-oocyte complexes were recovered from oviducts of superovulated females and used for immunization of rabbits. Altogether, 200 cumulus-oocyte complexes emulsified with complete Freund's adjuvant were used for priming, followed by 3 booster injections of 100 complexes in incomplete Freund's adjuvant administered at 3-week intervals. Hyperimmune rabbit serum was absorbed with prepubertal mouse ovaries to minimize non-specific reactivity and the immunoglobulin fraction of this absorbed hyperimmune serum was purified by affinity chromatography on Protein A-Sepharose (Pharmacia, Uppsala, Sweden). This fraction reacted specifically with cumuli oophori surrounding freshly ovulated mouse eggs up to dilutions over 1:1000 as assessed by indirect immunofluorescence.

Experimental protocols. Female mice aged 6-8 weeks were injected intraperitoneally with $0.5 \mathrm{mg}$ anti-cumulus $\mathrm{Ig}$ in $0.1 \mathrm{mg}$ Dulbecco's phosphate-buffered saline (Serva Feinbiochemica, Heidelberg, FRG) every 2 weeks. The antibody administration scheme and subsequent examinations involved two different experimental protocols and one control (Fig. 1).

In Exp. 1, anti-cumulus Ig $(0.5 \mathrm{mg})$ was administered 3 times at 2-week intervals. The injected females were caged with males for 4 consecutive days preceding the last antibody injection and examined for the presence of copulatory vaginal plugs during this period. This procedure was repeated twice at 2 -week intervals while $0.5 \mathrm{mg}$ non-specific rabbit immunoglobulin (Sigma, La Verpilière, France) was injected instead of anti-cumulus Ig (Fig. 1). The number of pregnant females after the first fertile mating period and the resulting litter size for each pregnant female were recorded. The animals were killed immediately after parturition and their ovaries were processed for histological examination (Fig. 1).

In Exp. 2, anti-cumulus Ig was substituted in the third injection with $0.5 \mathrm{mg}$ non-specific rabbit immunoglobulin (Sigma). Control mice were given repeated injections of $0.5 \mathrm{mg}$ non-specific rabbit immunoglobulin only (Fig. 1).

\begin{tabular}{|c|c|c|c|}
\hline Week & Exp. 1 & Exp. 2 & Control \\
\hline 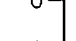 & Anti-cumulus Ig & Anti-cumulus Ig & Non-specific Ig \\
\hline & Anti-cumulus lg & Anti-cumulus Ig & Non-specific Ig \\
\hline & $\begin{array}{l}\text { Mating, plug assessment } \\
\text { Anti-cumulus Ig }\end{array}$ & $\begin{array}{l}\text { Mating, plug assessment } \\
\text { Non-specific lg }\end{array}$ & Non-specific ig \\
\hline $6-$ & $\begin{array}{l}\text { Mating, plug assessment } \\
\text { Non-specific lg }\end{array}$ & $\begin{array}{l}\text { Mating, plug assessment } \\
\text { Non-specific lg }\end{array}$ & $\begin{array}{l}\text { Mating, plug assessment } \\
\text { Non-specific lg }\end{array}$ \\
\hline $10-$ & $\begin{array}{l}\text { Mating, plug assessment } \\
\text { Non-specific lg }\end{array}$ & $\begin{array}{c}\text { Examination of litter size } \\
\text { Ovarian histology }\end{array}$ & $\begin{array}{c}\text { Examination of litter size } \\
\text { Ovarian histology }\end{array}$ \\
\hline & $\begin{array}{c}\text { Examination of litter size } \\
\text { Ovarian histology }\end{array}$ & & \\
\hline
\end{tabular}

Fig. 1. Scheme of experimental design including the timing of agent application and different examinations.

Histology. Ovaries were fixed for 3 days in Bouin's solution, dehydrated in a graded ethanol series and embedded in paraffin wax. Serial sections $(10 \mu \mathrm{m})$ were cut throughout the ovaries and stained with haematoxylin-Masson blue.

For quantitative examination, ovarian follicles were classified into three categories as to their developmental stage: primordial, growing non-antral, and antral. The wall of primordial follicles consisted of a single layer of flat or cuboidal cells. Growing non-antral follicles had several layers of granulosa cells but no follicular cavity. Follicles having at least begun the process of cavitation (assessed in adjacent serial sections) were classified as antral follicles. Healthy and atretic follicles were distinguished in all these categories using common histological criteria of follicular atresia (degeneration of the oocyte, high incidence of nuclear pycnosis in granulosa cells, cellular debris in the follicular cavity). Oocytes contained in different types of follicles were counted for each ovary in the largest-diameter section 
Table 1. Effects of anti-cumulus Ig on sexual behaviour, estabishment of pregnancy and litter size after a long-term passive immunization of mice

\begin{tabular}{|c|c|c|c|c|c|c|c|}
\hline \multirow[b]{2}{*}{ Treatment } & \multicolumn{3}{|c|}{$\begin{array}{l}\text { No. of females with } \\
\text { vaginal plugs }\end{array}$} & \multicolumn{3}{|c|}{$\begin{array}{l}\text { No. of pregnant } \\
\text { females }\end{array}$} & \multirow{2}{*}{$\begin{array}{l}\text { Litter size per } \\
\text { pregnant female* }\end{array}$} \\
\hline & Week 5 & Week 7 & Week 9 & Week 5 & Week 7 & Week 9 & \\
\hline $\begin{array}{l}\text { Exp. } 1 \\
(N=10)\end{array}$ & 9 & 10 & 9 & 0 & 0 & 9 & $12 \cdot 9 \pm 0 \cdot 9$ \\
\hline $\begin{array}{l}\text { Exp. } 2 \\
(N=10)\end{array}$ & 8 & 9 & $\mathrm{NCM}+$ & 0 & 9 & $\mathrm{NCM}^{\dagger}$ & $12 \cdot 7 \pm 0 \cdot 8$ \\
\hline $\begin{array}{l}\text { Control } \\
(N=10)\end{array}$ & $\mathrm{NCM}^{\dagger}$ & $\mathrm{NCM}+$ & 9 & $\mathrm{NCM} \dagger$ & $\mathrm{NCM}^{\dagger}$ & 9 & $12 \cdot 6 \pm 0.8$ \\
\hline
\end{tabular}

*Values are mean \pm s.e.m.

$+\mathrm{NCM}=$ not caged with males.

and in two other sections situated, respectively, at $100 \mu \mathrm{m}$ distances (leaving out 9 adjacent consecutive sections) in both directions of sectioning. Mean numbers of oocytes per section were calculated from these 3 sections for each ovary and each follicular category. These values are referred to as the number of oocytes per near-equatorial section and they serve as a basis for quantitative comparisons between treatment groups and controls.

Statistics. Intergroup and intragroup variance in the representation of different types of follicles in the ovaries was analysed by ANOVA. Means were compared using $t$ tests.

\section{Results}

The administration of $0.5 \mathrm{mg}$ anti-cumulus Ig repeated at 2-week intervals resulted in complete inhibition of fertility in the injected females throughout the treatment (Table 1). At the same time, there was no apparent effect of this treatment on the sexual activity as judged from daily assessments of vaginal plugs during the period for which the females were caged with males (Table 1). When anti-cumulus Ig was replaced with non-specific immunoglobulin at the third (Exp. 2) or fourth (Exp. 1) injection (Fig. 1), fertility was restored in 2 weeks. In both experimental groups, term pregnancies were achieved and the number of offspring resulting from them was not different from controls (Table 1).

The qualitative histological examination of ovaries taken from females after the young had been born did not reveal any apparent alteration of ovarian structure. In quantitative terms, oocytes contained in primordial and growing non-antral follicles were represented equally in both experimental groups and did not differ from controls. However, there was a slight but significant increase in the number of antral-follicle oocytes in the two experimental groups compared with controls (Fig. 2a). This increase was due to a higher proportion of atretic antral follicles in the antibody-treated animals (Fig. 2b). In other words, ovaries of the antibody-treated and control animals contained equal numbers of oocytes in healthy antral follicles but, in addition to them, the treated animals had elevated numbers of oocytes in antral follicles showing signs of atresia. In contrast, no increase in follicular atresia due to anti-cumulus Ig treatment was observed for primordial and growing non-antral follicles (Fig. 2b).

\section{Discussion}

The experiments described here were undertaken as a prelude to an active immunization study, to determine whether prolonged action of anti-cumulus oophorus antibodies administered at a dose sufficient to block fertility completely produces any detectable side-effects concerning the functional 


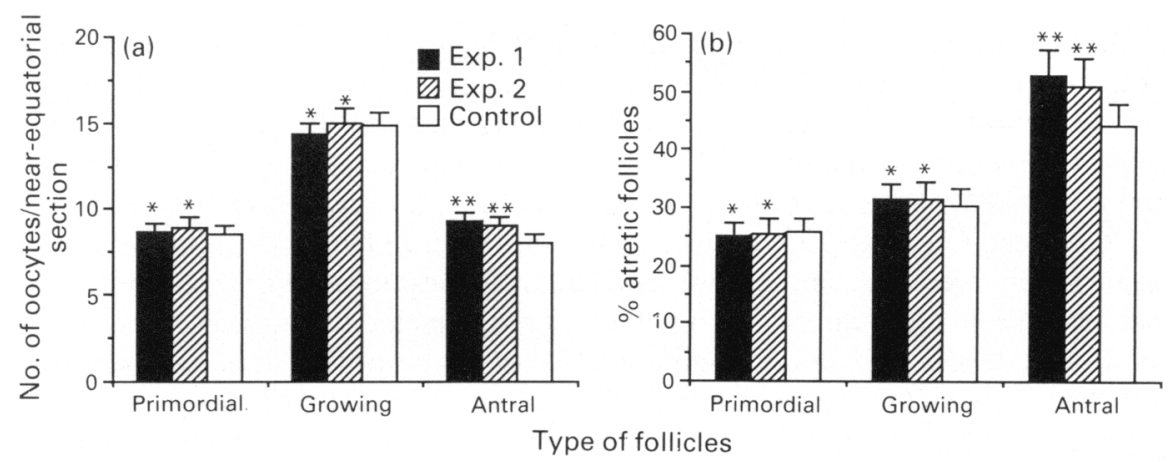

Fig. 2. Effects of anti-cumulus antibody treatment on ovarian histology. (a) Quantitative representation of oocytes contained in different types of follicles in near-equatorial ovarian sections of antibody-treated and control animals. (b) Percentage of follicular atresia in different follicular categories assessed in near-equatorial ovarian sections of antibody-treated and control animals. Values are means \pm s.e.m. ${ }^{*}$ Not significantly different from control $(P>0.05)$; ** Significantly different from control $(P<0.05)$.

integrity of the reproductive system. The persistence of complete fertility inhibition throughout the treatment is proof of the maintenance of contraceptive levels of anti-cumulus antibodies in the immunized animals between individual antibody applications.

No changes in the sexual behaviour of antibody-treated mice were observed compared with controls. This implies the absence of serious hormonal disturbances which would be incompatible with the normal oestrous cycle. The possibility of oestrus under the conditions of prolonged anticumulus antibody action was doubted because of the considerable decrease in the number of ovulated eggs after a single antibody injection applied to mice on the day of PMSG treatment in the superovulation regimen; this decrease was apparently due to interference of anti-cumulus antibodies with the final phases of preovulatory follicular development (Tesarik et al., 1990b). However, in that study, the anti-cumulus oophorus antibodies bound preferentially to cumulus-oocyte complexes and not to mural granulosa cells or to other ovarian structures. Preovulatory follicles may therefore continue virtually normal steroid production under the action of anti-cumulus antibodies even if they are not able to produce and release normal mature eggs.

Reversibility of the anti-cumulus antibody effect on the reproductive performance in mice after a single administration has been described previously (Tesarik et al., 1990b). In this study we were unable to demonstrate any persistent impairment of fertility when the treatment was stopped after maintaining contraceptive levels of circulating antibodies for as long as 6 weeks. Unlike anti-zona pellucida antibodies, which firmly bind to the zona pellucida of ovarian oocytes that have not yet been recruited from the quiescent oocyte pool and consequently produce prolonged infertility even after a single antibody administration (Tsunoda \& Sugie, 1977; Sacco, 1979), purified anti-cumulus antibodies are only retained in the cumulus-oocyte complex of large preovulatory follicles (Tesarik et al., 1990b). Therefore, all preovulatory follicles that develop after the elimination of circulating antibodies are very probably antibody-free. This might explain the relatively rapid restoration of fertility after the cessation of anti-cumulus antibody administration observed in the present study.

The evaluation of ovarian histology did not show any changes in the structure and quantitative representation of primordial and growing preantral follicles which could be ascribed to the anticumulus antibody action. However, there was a slight increase in the number of antral follicles in the antibody-treated animals and this increase was due to a higher incidence of atresia in this follicular category. Since the ovaries for histological examination were taken from animals whose fertility had been completely restored after the cessation of anti-cumulus antibody treatment, this isolated increase in follicular atresia concerning specifically antral follicles was clearly due to a rather remote previous antibody effect on ovarian follicular development. As it has been shown 
that anti-cumulus antibodies reduce the ovulation rate by an effect that is limited to large antral follicles (Tesarik et al., 1990b), this increase in the number of atretic antral follicles is most probably due to the persistence of follicles that have been arrested in their preovulatory development during the previous antibody treatment. This finding does not represent a serious side-effect of the antibody treatment because the atretic follicles do not accumulate in the ovaries (no difference between Exps 1 and 2; see also Fig. 2) and are probably soon resorbed. In fact, no significant increase in the ovarian size was observed in the antibody-treated animals (unpublished observations).

In conclusion, prolonged administration of antibodies directed to antigens of the periovulatory cumulus oophorus do not seem to deplete the stock of ovarian oocytes, do not cause any apparent endocrine disturbances and do not compromise future conception. These findings are important for interpretation of future active immunization studies. If active immunization with cumulus antigens brings about eventual adverse and irreversible effects on reproductive function, this will be most probably due to an aberrant immune response to injected autoantigen and not to a specific effect of cumulus-directed antibodies.

Support for this project [CSA-89-045] was provided by the Contraceptive Research and Development Program (CONRAD), Eastern Virginia Medical School under a Cooperative Agreement with the United States Agency for International Development (U.S.A.I.D.) (DPE-3044-A-00-6063-00). The views expressed by the authors do not necessarily reflect the views of U.S.A.I.D. and CONRAD.

\section{References}

Aitken, R.J., Rudak, E-A., Richardson, D.W., Dor, J., Djahanbahkch, O. \& Templeton, A.A. (198I) Influence of anti-zona and anti-sperm antibodies on sperm-egg interactions. J. Reprod. Fert. 62, 597-606.

East, I., Mattison, D.R. \& Dean, J. (1984) Monoclonal antibodies to the major protein of the murine zona pellucida: effects on fertilization and early development. Devl Biol. 104, 49-56.

East, I., Gulyas, B.J. \& Dean, J. (1985) Monoclonal antibodies to the murine zona pellucida protein with sperm receptor activity: effects on fertilization and early development. Devl Biol. 109, 268-273.

Gulyas, B.J., Gwatkin, R.B.L. \& Yuan, L.C. (1983) Active immunization of Cynomolgus monkeys (Macaca fascicularis) with porcine zonae pellucidae. Gamete Res. 4, 299-307.

Henderson, C.J., Hulme, M.J. \& Aitken, R.J. (1988) Contraceptive potential of antibodies to the zona pellucida. J. Reprod. Fert. 83, 325-343.

Mahi-Brown, C.A., Huang, T.T.F., Jr \& Yanagimachi, R. (1982) Infertility in bitches induced by active immunization by porcine zonae pellucidae. J. exp. Zool. 222, 89-95.

Mahi-Brown, C.A., Yanagimachi, R., Hoffman, J.C. \& Huang, T.T.F., Jr (1985) Fertility control in the bitch by active immunization with porcine zonae pellucidae: use of different adjuvants and patterns of estradiol and progesterone levels in estrous cycles. Biol. Reprod. 32, $761-772$.

Mahi-Brown, C.A., Yanagimachi, R., Nelson, M.L., Yanagimachi, H. \& Palumbo, N. (1988) Ovarian histopathology of bitches immunized with porcine zonae pellucidae. Am. J. Reprod. Immunol. Microbiol. 18, 94-103.

Meizel, S., Pillai, M.C., Diaz-Perez, E. \& Thomas, P. (1990) Initiation of the human sperm acrosome reaction by components of human follicular fluid and cumulus secretions including steroids. In Fertilization in Mammals, (in press). Eds B. D. Bavister, J. M. Cummins \& E. R. S. Roldan. Plenum, New York.

Sacco, A.G. (1979) Inhibition of fertility in mice by passive immunization with antibodies to isolated zonae pellucidae. J. Reprod. Fert. 56, 533-537.

Sacco, A.G., Subramanian, M.G., Yurewicz, E.C., DeMayo, F.J. \& Dukelow, W.R. (1983) Heteroimmunization of squirrel monkeys (Saimiri sciureus) with a purified porcine zona antigen (PPZA): immune response and biologic activity of antiserum. Fert. Steril. 39, 350-358.

Sacco, A.G., Pierce, D.L., Subramanian, M.G., Yurewiz, E.C. \& Dukelow, W.R. (1987) Ovaries remain functional in squirrel monkeys (Saimiri sciureus) immunized with porcine zona pellucida 55000 macromolecule. Biol. Reprod. 36, 481-490.

Siteri, J.E., Dandekar, P. \& Meizel, S. (1988) Human sperm acrosome reaction-initiating activity associated with the human cumulus oophorus and mural granulosa cells. J. exp. Zool. 246, 71-80.

Skinner, S.M., Mills, T., Kirchick, H.J. \& Dunbar, B.S. (1984) Immunization with zona pellucida proteins results in an abnormal ovarian follicular differentiation and inhibition of gonadotropin-induced steroid secretion. Endocrinology 115, 2418-2432.

Tesarik, J. (1989) Immunoinhibition of human fertilization in vitro by antibodies to the cumulus oophorus intercellular matrix. J. Reprod. Fert. 87, 1193-198.

Tesarik, J. \& Testart, J. (1989) Human sperm-egg interactions and their disorders: implications in the management of infertility. Hum. Reprod. 4, 729-741. 
Tesarik, J., Pilka, L., Drahorad, J., Cechova, D. \& Veselsky, L. (1988) The role of cumulus cell-secreted proteins in the development of human sperm fertilizing ability: implication in IVF. Hum. Reprod. 3, 129-132.

Tesarik, J., Mendoza Oltras, C. \& Testart, J. (1990a) Effect of the human cumulus oophorus on movement characteristics of human capacitated spermatozoa. $J$. Reprod. Fert. 88, 665-675.

Tesarik, J., Testart, J., Leca, G., Nomé, F. (1990b) Reversible inhibition of fertility in mice by passive immunization with anticumulus oophorus antibodies. Biol. Reprod. 43, (in press).
Tsunoda, Y. \& Sugie, T. (1977) Inhibition of fertilization in mice by anti-zona pellucida antiserum. Jap. J. Zootech. Sci. 48, 784-790.

Tsunoda, Y., Sugie, T., Mori, J., Isojima, S. \& Koyama, K. (1981) Effect of purified zona antibody on fertilization in the mouse. J. exp. Zool. 271, 103-108.

Wood, D.M., Liu, C. \& Dunbar, B.S. (1981) Effect of alloimmunization and heteroimmunization with zonae pellucidae on fertility in rabbits. Biol. Reprod. 25, 439-450.

Received 18 April 1990 